\title{
Asexual reproduction, fragmentation, and skeletal morphology of a plexaurid gorgonian
}

\author{
Howard R. Lasker \\ Department of Biological Sciences, State University of New York at Buffalo, Buffalo, New York 14260, USA
}

\begin{abstract}
The Caribbean gorgonian Plexaura A, a species of uncertain affinity, relies almost entirely on asexual reproduction for the formation of new colonies. At a site of the San Blas Islands, Panama, $94 \%$ of the colonies $<10 \mathrm{~cm}$ in height had apparently developed from fragments of larger colonies. These fragments were formed when branches broke off from Plexaura A colonies. In situ tests of the force required to break off branches indicate that downward directed forces of as low as 0.1 Newton induced failure of Plexaura A branches. In contrast, branches of equivalent diameter of the sympatric congenor $P$. homomalla (Esper) frequently remained unbroken at forces up to $19.6 \mathrm{~N}$. Most fragments broke off the colony at points exhibiting a constriction in the axial skeleton. Constrictions in the branch axis of Plexaura A were not distributed uniformly on the colony. Branch points distant from the branch tip were more likely to have axis constrictions than those close to the tip. Fragments are believed to be produced by wave action during squalls and loose fragments were regularly found at the study site. These data suggest the axis constrictions in Plexaura A may be an adaptation for enhanced asexual reproduction.
\end{abstract}

\section{INTRODUCTION}

The relative advantages and disadvantages of clonal and colonial growth forms have received increasing attention in the last few years (Harper, 1977; Jackson, 1977; Highsmith, 1982; Cook, 1983; Coates and Jackson, in press). An important characteristic of clonal organisms is their ability to 'regenerate' large populations from a small number of individuals. This regenerative ability is particularly great among physiologically integrated colonial forms, in which growth and survival are functions of colony size (Hughes and Jackson, 1980). Thus, colonial species probably can survive and recover from periods of high mortality more readily than aclonal, solitary organisms (Highsmith, 1982).

Among colonial forms the ability of a colony to regenerate itself from a small fragment of the colony provides not only a means of enhancing colony survival but also a means of further propagating and dispersing the clone. Propagation of this type occurs when fragments of colonies break off from a 'parent' colony and then continue to grow as independent colonies. In severe situations, like hurricanes, the forces responsible for fragmentation lead to the death of most of the colony (Knowlton et al., 1981; Woodley et al., 1981). In other cases, however, many of the fragments survive and become separate colonies, each of which can grow to a size equal to or greater than that of the colony from which it was derived. Fragmentation occurs in a wide variety of taxa but has been most thoroughly documented in the corals (Glynn et al., 1972; Gilmore and Hall, 1976; Wilson, 1979; Highsmith, 1982; Highsmith et al, 1980; Bothwell, 1981; Knowlton et al., 1981; Tunnicliffe, 1981, 1982; Lasker, 1983). Among these species fragmentation can enhance the growth of the clone whenever growth of the newly formed colonies exceeds the mortality of unattached fragments. In such cases fragmentation is beneficial and should be selected for.

The presence of fragmentation in a group of species and their apparent success does not demonstrate an 'advantage' for this mode of propagation nor does it demonstrate selective processes. A more convincing, though circumstantial, argument can be made for those species which also exhibit unusual morphologies that facilitate fragmentation. Tunnicliffe (1981, 1982) examined Acropora cervicornis and concluded that $A$. cervicornis, 'is able to use an inherent weakness' to promote growth of the clone (Tunnicliffe, 1982). A more dramatic example of an apparent adaptation for fragmentation has been described in the Pacific gorgonian Junceela fragilis by Walker and Bull (1983). They 
found that $J$. fragilis produces small fragments by resorbing tissue several centimeters below the branch tip. The end of the branch then breaks at the weakened point and reattaches, forming a new colony.

In this paper I report another case of a gorgonian which relies on fragmentation to generate new colonies and which exhibits unusual morphologic characteristics which facilitate fragmentation. The species, a Plexaura sp. of uncertain affinity, is similar to Plexaura homomalla forma kukenthali. The species is morphologically distinct from $P$. homomalla and may represent a new species or a hitherto synonomized species (F. M. Bayer, pers. comm.). For the purpose of identification I shall refer to this species as Plexaura A. Plexaura A can be distinguished from $P$. homomalla on the basis of the absence of a calicular lip, reduced polyp armature, straighter and simpler spindles and thicker, less foliate leaf clubs. The species is known from the San Blas Islands, Panama and the Florida Keys. Plexaura A differs from $P$. homomalla in one other important character. P. homomalla terminal branches are, as in most gorgonians, extremely flexible and considerable force is required to break off a branch. In contrast, Plexaura A branches are brittle and can be snapped off a colony with little effort. The brittleness of Plexaura A colonies is rare among Caribbean gorgonians and is unique among Plexaura species. In this study I show how the brittleness of Plexaura A branches greatly facilitates failure of the branches and thereby promotes the propagation of the species.

\section{METHODS}

Fragmentation was studied in a Plexaura A population located on Korbiski Reef near the Smithsonian Tropical Research Institute field station in the San Blas Islands, Panama. The gorgonian population was located at the northeastern end of the reef in water 0.5 to $4 \mathrm{~m}$ deep. The area features consolidated coral rock, coral heads (Diploria spp.) and pockets of sand. The study site, a $10 \times 10 \mathrm{~m}$ area, was densely populated by the gorgonians Plexaura A, Plexaura homomalla (Esper), Pseudopterogorgia americana (Gmelin), Pseudoplexaura porosa (Houttuyn), Plexaura flexuosa (Lamouroux) as well as other species. Plexaura A densities within $1 \times 1 \mathrm{~m}$ grids ranged from 0 to 34 colonies $\mathrm{m}^{-2}$.

All Plexaura A colonies within the $100 \mathrm{~m}^{2}$ area were included in the study. The height of each colony was measured and the base of the colony was carefully examined to determine whether the colony had developed from a reattached fragment. Colonies which originated from fragments were usually attached to the substrate at several points and often had several par- allel branches growing up from a branch lying in the substrate (Fig. $1 \mathrm{~A}$ ). These colonies were distinctly different in appearance from those developing from a larva. Larva-originated colonies had a single point of attachment and a single branch rising from the base (Fig. 1B). The origin of colonies could most readily be determined among small colonies, since large colonies had enlarged holdfasts which obscured the origin of the colony. The holdfasts of large colonies also contained branches which probably had become reattached to the holdfast. Due to the difficulty of determining the origin of the larger colonies only those $\leq 10 \mathrm{~cm}$ height were considered in the analysis of colony origin.

In order to quantify the ability of Plexaura A to fragment, 2 simple mechanical tests were performed on branches of both Plexaura A and, for contrast, $P$. homomalla. The first of the experiments was conducted on colonies in situ at Korbiski Reef. In this experiment a branch was arbitrarily chosen and a spring scale attached with a cable tie to a point $5 \mathrm{~cm}$ above the branch's point of insertion. Force was then directed downward while the branch was held in place just below its point of insertion (Fig. 2). The force required to break the branch axis was recorded from the scale at the moment of failure. The maximum force applied to a branch was 19.6 Newtons (the maximum force the scale would record). Twenty branches on each of 3 Plexaura A and 2 P. homomalla colonies were tested in this fashion. At the time of the experiment the branch order (the maximum number of branch points between a point and the branch terminus; Fig. 3) was also recorded. Thickness of the axis $0.5 \mathrm{~cm}$ above the branch point was measured to the nearest $0.05 \mathrm{~mm}$ with vernier calipers at a later time.

The second experiment was conducted in sea water alongside a dock, using freshly collected Plexaura A and $P$. homomalla colonies. In these experiments a branch point was selected and the branch held above and below its point of insertion. Force was then applied normal to the branch. The force was kept normal to the bending branch by rotating the colony as the force was applied (Fig. 2). The branch was not allowed to bend beyond an angle of $180^{\circ}$. The force required to break the branch as well as the original and final branch angles were all noted. In 30 cases the branch which had been broken from the colony was itself tested to determine the force required to break the branch into 2 pieces.

Examination of the fragments generated in the experiments as well as those collected in the field indicated that branches frequently broke at thin points in the branch axis. In order to document the existence of these morphological features three colonies of Plexaura A and one of P. homomalla were collected, strip- 


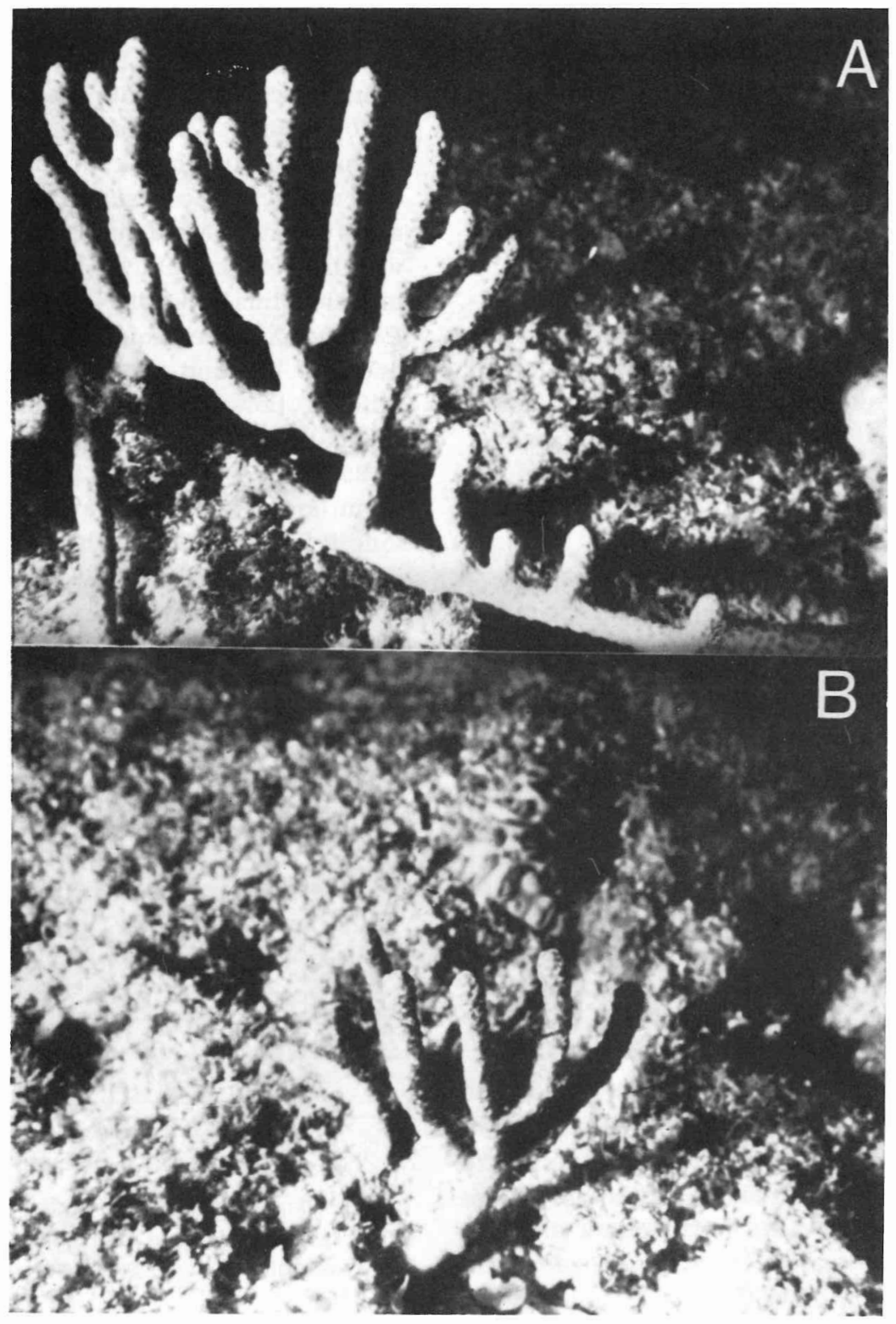

Fig. 1. Plexaura A. Colonies which developed from a fragment (A) and from a larva (B)

ped of coenenchyme and the axis of each branch examined for the presence of thin points. The colonies were subsequently broken apart at their branch points and the thickness of each branch measured at the break and $0.5 \mathrm{~cm}$ above the break. In 2 cases ( 1 colony of each species) minimum and maximum diameters were measured. Only minimum diameters of the remaining 2 Plexaura A colonies were measured.

The size and abundance of naturally occurring fragments were determined from a collection of all living unattached fragments. The length and number of all fragments were determined and axis diameters at the break point and $0.5 \mathrm{~cm}$ above the break point were measured with a vernier caliper.

\section{RESULTS}

\section{Frequency of asexual reproduction}

The size-frequency distribution of Plexaura A colonies is presented in Fig. 4. Although a number of colonies reached heights of $1 \mathrm{~m}$ or greater the majority of colonies were small and $25 \%$ of the 212 colonies were less than $10 \mathrm{~cm}$ in height. Of the $\leq 10 \mathrm{~cm}$ tall colonies $94 \%$ appeared to have developed from fragments. In contrast, only 19 P. homomalla colonies were found in the $100 \mathrm{~m}^{2}$ area and all were greater than $10 \mathrm{~cm}$ in height. None appeared to have developed from fragments. 

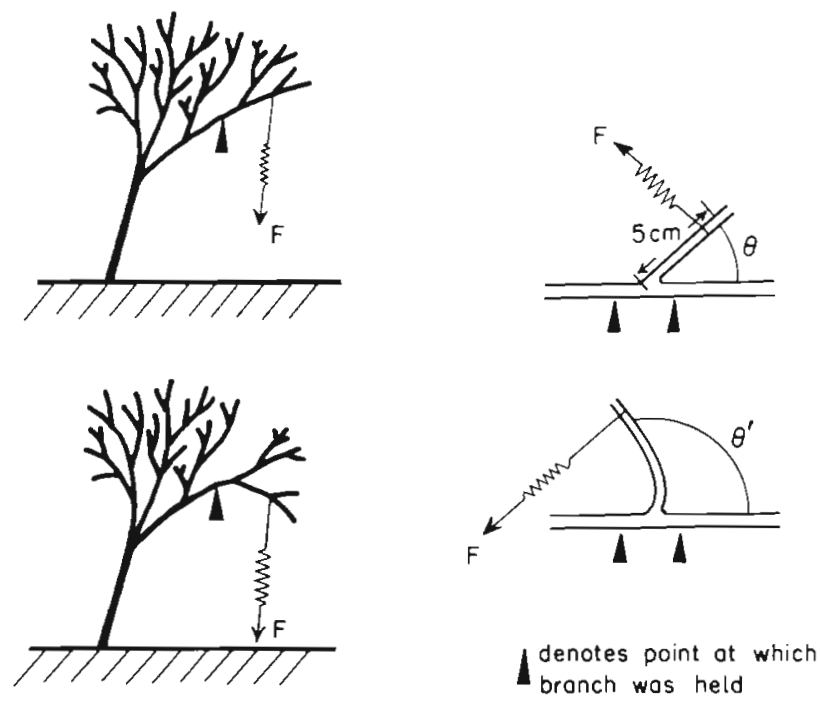

Fig. 2. Procedure used to test the breaking strength of gorgonian colonies. See text for explanation. In situ experiments depicted on the left, dockside experiments on the right

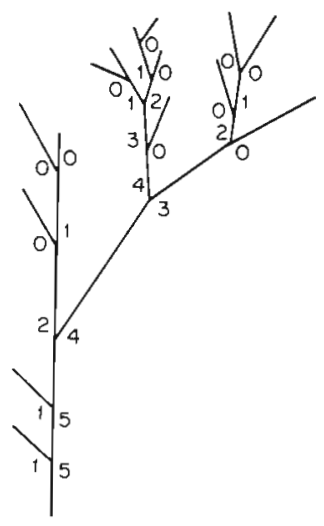

Fig. 3. Ranking of branches and branch points based on the number of junctions between a point and the farthest branch tip

\section{Breaking experiments}

The breaking experiments indicate that the large numbers of fragment-formed Plexaura A colonies can be related to the ease with which fragments can be produced. As is apparent in Fig. 5 Plexaura A branch points broke more easily than those of $P$. homomalla regardless of the branch axis diameter. The forces required to break off branches of the 2 species differed significantly (Mann-Whitney $U$ test, $p<0.0001$ ). Branch axis diameter was significantly correlated with breaking force among Plexaura A colonies ( $r=0.43$, $p<0.01$ ), but was not correlated with breaking force among P. homomalla colonies. The weakness of Plexaura A branches is again evident in Fig. 6, which compares breaking force with respect to branch rank. Plexaura A branches broke off at lower forces than $P$. homomalla branches regardless of rank (t-tests at each rank, all $\mathrm{p}<0.001$ ). The force required to break off branches correlated with branch rank (Plexaura A, I = $0.50, \mathrm{p}<0.001-P$. homomalla, $\mathrm{r}=0.48, \mathrm{p}<0.005)$.

The dockside breaking experiments yielded data very similar to the in situ experiments. In the dockside experiments the maximum force applied to branches was 9.8 Newtons. Only 1 of the 20 Plexaura homomalla branch points broke at a force of 9.8 Newtons. All of the Plexaura A branch points fractured at lower forces. The angle of bending at which the branches failed also differed between the 2 species. The Plexaura A branches failed after they had been dislocated a mean of $85^{\circ}$ (S.D. $=20^{\circ}, \mathrm{n}=53$ ), the maximum dislocation required to break off a branch was $120^{\circ}$. In contrast, the lone $P$. homomalla branch point which failed had been displaced $140^{\circ}$ at the time of failure and in the other cases the branches were bent parallel to the branch they inserted into without inducing failure (a dispiacement of 150 to $160^{\circ}$, depending on the original branch angle)

The strength of branches at points other than the branch point was also tested in the dockside experiments. Repeated attempts to break Plexaura ho-

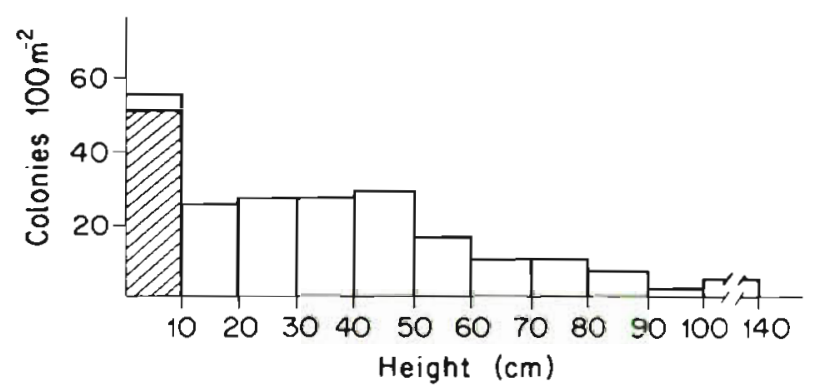

Fig. 4. Plexaura A. Size-frequency distribution of colonies on Korbiski Reef. Hatched area: colonies formed from fragments. Only colonies $\leq 10 \mathrm{~cm}$ are classified according to their origin

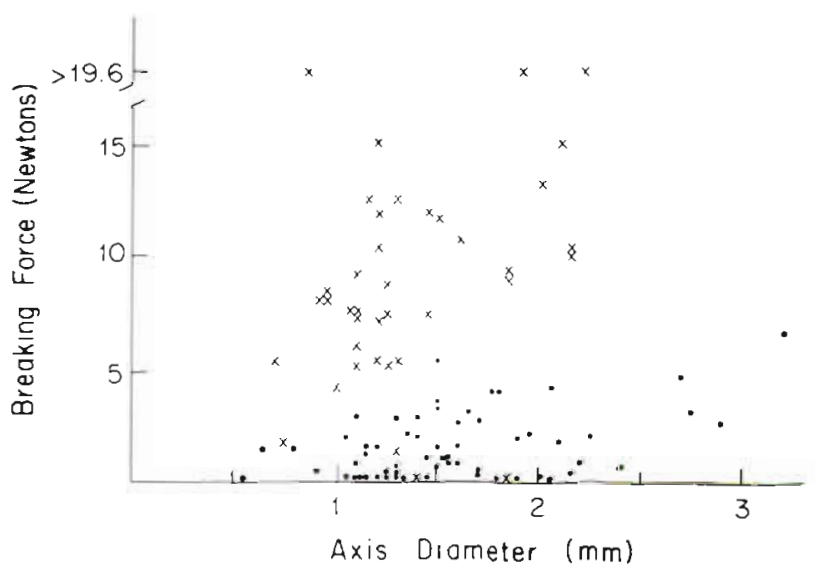

Fig. 5. Force required to break branches of Plexaura A (dots) and of $P$. homomalla (crosses) from the colony. Axis thickness was measured $0.5 \mathrm{~cm}$ above the break. The maximum force applied to the branch was 19.6 Newtons 


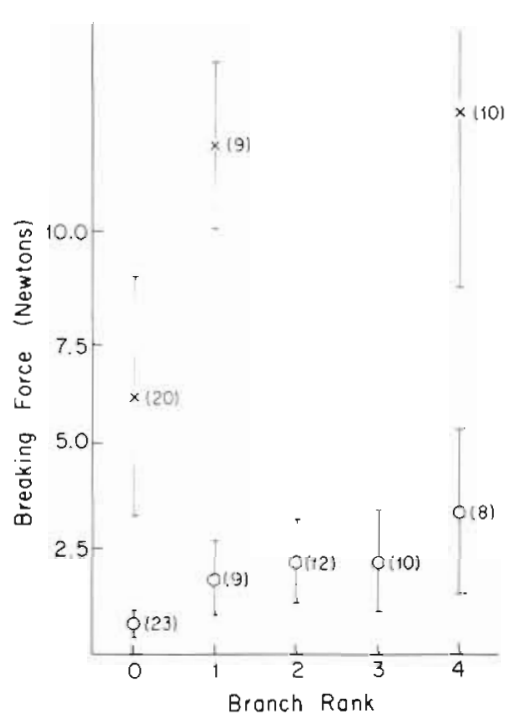

Fig. 6. Force (mean $\pm 95 \%$ confidence interval) required to break Plexaura A (circles) and P. homomalla (crosses) as a function of branch rank. (See Fig. 3 for explanation of branch rank)

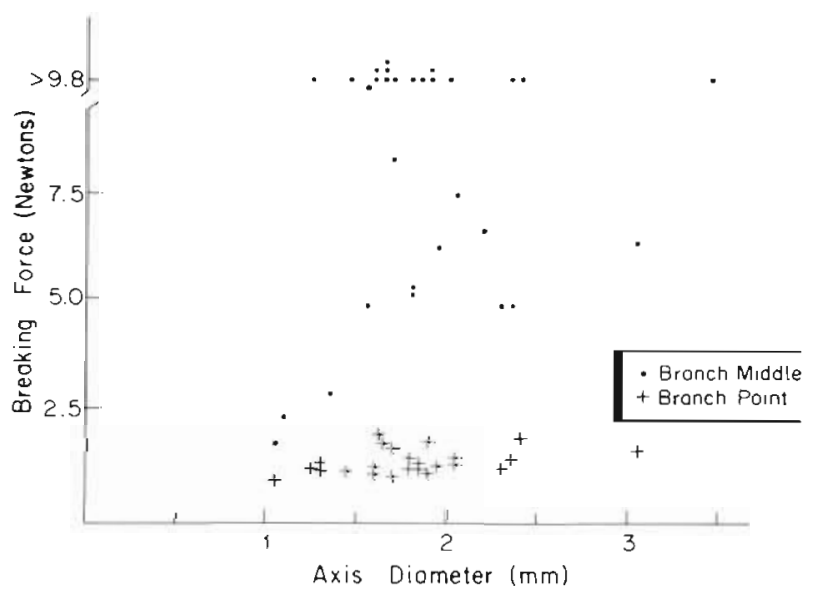

Fig. 7. Plexaura A. Force required to break branches from colonies at the branch point and force required to break those same branches in half

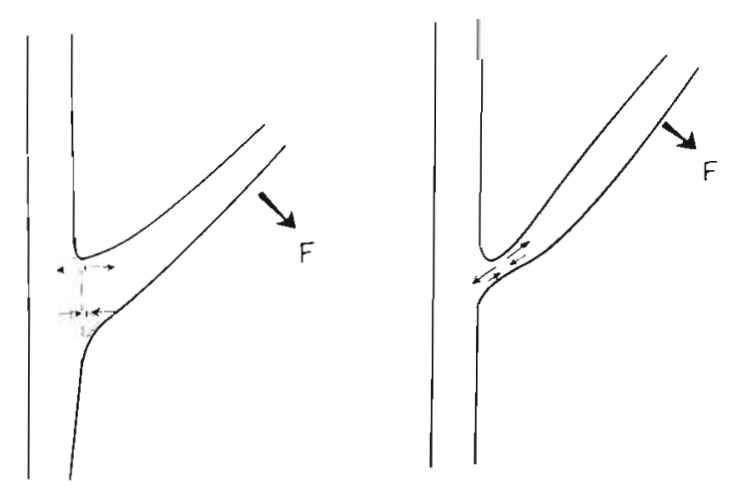

Fig. 8. Schematic representation of branch points with and without axis constrictions, and of the stresses encountered at the branch point momalla branches failed. Plexaura A branches of similar diameter regularly broke at forces under $9.8 \mathrm{~N}$, and in every case the force required to break branches was greater at the middle of the branch than at the branch point (Fig. 7).

\section{Axis morphology}

Analysis of the axial skeletons again revealed differences between the 2 species. Plexaura homomalla branch axes were round to elliptical in cross section and smoothly tapered from the base to the branch tips. An exception to this pattern occurred at the branch points, many of which were slightly compressed in the plane of branching (Fig. 8). As a consequence of the compression minimum diameter of the axis was lower at the branch point than above it, but maximum diameter was greater at the branch point. An estimator of cross-sectional area was calculated by multiplying minimum and maximum diameter. This index provides an estimator of the amount of gorgon laid down. Using that index $84 \%$ of the 89 measured $P$. homomalla branches were thicker at the branch point than $0.5 \mathrm{~cm}$ higher. Analysis based on maximum and minimum diameters separately indicate that 92 and $46 \%$ branches respectively were thicker at the branch point.

Plexaura $\mathrm{A}$ axes were notably different in appearance from those of $P$. homomalla. Plexaura A axes often had a sinuous appearance and tended to be elliptical or rectangular in cross section. Axis diameter thinned toward the branch tips but diameter fluctuated along the length of the branch. Constrictions in axis diameter were especially conspicuous at the branch points (Fig. 8). The constrictions were evident in analyses using cross-sectional area, minimum, and maximum diameter. The index of cross-sectional area (maximum $x$ minimum diameter) of 133 branches, measured on one colony, revealed constrictions in $79(55 \%)$ of the branch points (vs. $16 \%$ of the $P$. homomalla branch points). Estimates of the abundance of constrictions using maximum and minimum diameter were 41 and $55 \%$, respectively. Constrictions of the axis at the branch point were not distributed randomly among branch points (Fig. 9). The proportion of branch points with constrictions tended to increase with branch rank. The distribution was significantly different from random expectations $\left(x^{2}=16.74, p<0.005, \quad d f=3\right)$. Although higher order branches had axis constrictions in disproportionate numbers, the greatest absolute number of constrictions occurred among the $1^{\circ}$ and $2^{\circ}$ branches ( 15 branches with constrictions in each class).

Minimum axis diameter was a good index of constrictions among Plexaura A colonies and minimum axis diameters of 2 additional colonies were also meas- 


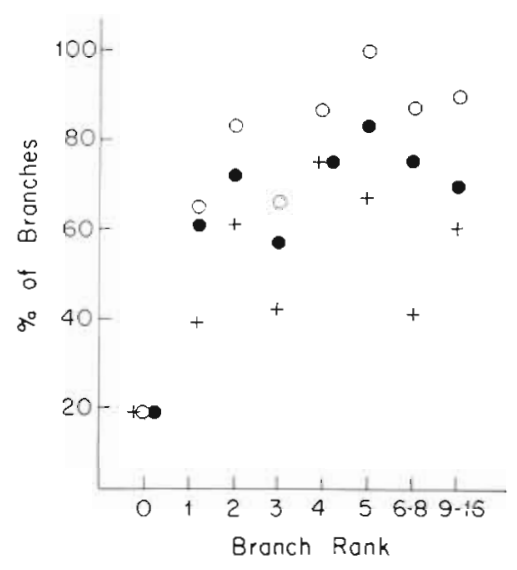

Fig. 9. Distribution of branch points with axis constrictions as a function of rank. Presence of axis constrictions was determined by measures of area (o) minimum diameter ( $\bullet$ ) and maximum diameter $(+)$

ured. These colonies, designated Colonies 2 and 3 , aİso exhibited many branch points with constrictions (48 and $47 \%$, respectively). Constrictions in axis diameter were not randomly distributed among branches on Colony $2\left(\mathrm{x}^{2}=11.47, \mathrm{p}<0.025, \mathrm{df}=3\right)$. As in the previously described colony, constrictions were proportionately most abundant among higher rank branches and absolutely most abundant among $1^{\circ}$ branches. Constrictions in axis diameter in Colony 2 were not randomly distributed with respect to axis diameter either $\left(\mathrm{x}^{2}=8.11, \mathrm{p} 0.05, \mathrm{df}=3\right)$. Thicker branches were most likely to have branch points with constrictions among both colonies. Constrictions at the branch points of Colony 3 were randomly distributed with respect to both branch rank $\left(\mathrm{x}^{2}=0.99\right.$, $p>0.5$, df $=3)$, and diameter on Colony $3\left(x^{2}=6.66\right.$, $0.1>p>0.05, \mathrm{df}=3$ ).

\section{Fragmentation at Korbiski}

Fragment size frequency distributions based on number of branches (Fig. 10) as well as length of the

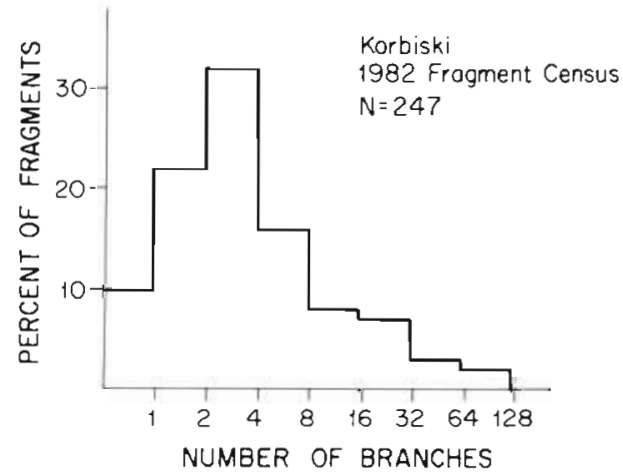

Fig. 10. Plexaura A. Size-frequency distribution of naturally occurring fragments collected on $100 \mathrm{~m}^{2}$ in July, 1982 fragment indicate that intermediate sized fragments are most common. Comparison of the distribution of sizes with that of axis constrictions on intact colonies (Fig. 9) indicates that fragments produced by breaking $0^{\circ}$ branches (1 branch) are underrepresented in the field collection. Naturally occurring fragments were also more likely to have axis constrictions at the point of fracture than are randomly chosen branch points on an intact colony. Using minimum diameter as an index of axis constriction the 3 measured, intact colonies had constrictions at $54 \%$ of the branch points $(\mathrm{N}=388$, $95 \%$ confidence interval $=50$ to $58 \%$ ). Naturally occurring fragments had constrictions at their bases in $82 \%$ of the cases $(N=138,95 \%$ confidence interval $=73$ to $89 \%$ ). Fragments with constrictions at their bases were distributed uniformly with respect to branch rank $\left(x^{2}=0.66, p>0.9, d f=4\right)$.

\section{DISCUSSION}

Plexaura A unlike $P$. homomalla, and unlike most gorgonian species, produces most new colonies from fragments. The success of this mode of asexual propagation can be attributed to the ability of Plexaura A colonies to generate fragments, and the fragmentation of Plexaura A colonies can be attributed to both the morphology and brittleness of the branches. These traits are evident in the comparison of Plexaura A and P. homomalla.

Plexaura A branches are more brittle than those of $P$. homomalla. When 30 straight sections of Plexaura A were tested for strength only $53 \%$ could be bent $180^{\circ}$ and could resist an applied force of $9.8 \mathrm{~N}$. In contrast tests of similar sized $P$. homomalla branches indicated that $100 \%$ of the branches could be bent in such a fashion. In many cases $P$. homomalla branches could be tied in a knot and still did not fracture.

The branch morphology of the two species also differed and that further affected fragmentation. The effects of morphology on fragmentation can be recognized in an analysis of the process of failure of a branch. Wainwright et al. (1976), Koehl (1976, 1977) and Vosburgh (1977) have analysed stresses in forms like in gorgonians as cantilevers. Failure in such structures occurs when either the tensile or shear stress on a branch exceeds the strength of the structure. The experiment testing the strength of straight branches indicated that the 2 species differ in their inherent strengths. In addition the morphology of the 2 species suggests that equivalent forces applied to branches of each produces greater stresses in Plexaura A branches. In all of the experiments force was applied to a point $5 \mathrm{~cm}$ above the branch point thus the bending moment applied to the 2 species was equivalent for a given 
force. However, the second moment of area of Plexaura A branch points is often less than that of $P$. homomalla because the area of many Plexaura A branch points is less than that of the branch axis above the branch point. Orientation of the branch further affects the second moment of area. Plexaura A again have smaller second moments of area than equal area equivalent $P$. homomalla branches, since cross sections of Plexaura A branch points are frequently compressed such that the long axis is horizontal and therefore normal to downward directed forces (Fig. 8). In contrast, $P$. homomalla branch points are compressed such that the long axis is parallel to downward directed forces. These features increase the second moment of area in $P$. homomalla axes and decrease it in Plexaura A axes. Tensile stress is inversely related to the second moment of area (Koehl, 1977) and as a consequence Plexaura A branches should experience greater tensile stresses than similar $P$. homomalla branches. Since the axes of both species fail on their upper surface it is believed that tensile stress leads to failure (as opposed to the shear stress exerted on the underside of the branch).

Plexaura A colonies had branches which were more brittle than Plexaura homomalla and had a morphology which further facilitated fragmentation. The question then arises whether Plexaura A morphology can be used to predict the pattern of breaking observed in nature. The pattern of branching in Plexaura A colonies is intermediate to both lateral and dichotomous branching patterns. Consequently, the number of branches increases geometrically as branch order decreases. This suggests that fragmentation should occur most commonly among the thinner lower order branches, which contain the greatest number of axis constrictions.

The manner in which forces are applied to colonies suggests, however, that larger, higher order branches should break more readily. The primary force responsible for breakage in Plexaura A colonies at Korbiski is probably drag on branches exerted by turbulent water movements during wet season squalls (maximum wind speeds of 55 to $95 \mathrm{~km} \mathrm{~h}^{-1}$ ). During these squalls high rank branch points, which have more branches, are subject to greater forces and those forces are applied over greater lever arms (i.e. greater bending moment). Therefore, high rank branch points should be under greater stress than low rank branch points. Furthermore, the turbulence of the wave action is apt to apply forces in different directions to the same colony. The further apart the branches the more likely they are to receive forces from different directions. Therefore, high order branches are more apt to be 'pulled apart' than closely associated low rank branches. This latter point is important since forces applied uniformly to the entire colony primarily stress the colony holdfast and only create small stresses at the branch points.

The distribution of thin points on Plexaura A colonies suggests small fragments formed by breakage at low rank branch points should be most common. In contrast, the effects of turbulent currents on the colony suggests the colonies should fail at high rank branch points. The fragments collected in July, 1982 were most commonly of intermediate size and the small fragments expected from 0 and $1^{\circ}$ branches were notably rare. This pattern may relate to the distribution of forces on the colonies or may relate to the greater probability of transport and burial which small fragments are subject to (unpubl. data).

The presence of large number of fragment formed colonies, the brittle axis of Plexaura A and the thin points on the axis demonstrate that Plexaura A morphology promotes asexual colony propagation. However, the brittle skeleton of Plexaura A may serve additional purposes. A common cause of mortality among gorgonian colonies is the toppling of the colony due to failure of the substrate which the holdfast is anchored to (Birkeland, 1974; Kinzie, 1974). Smaller colonies on which currents exert less drag are less likely to fail in this manner. The brittle skeleton of Plexaura A could effect a reduction in drag and thereby reduce whole colony mortality. This hypothesis is not mutally exclusive with the proposal that brittleness has been selected to further asexual reproduction, but it illustrates the difficulties of studying 'adaptations' using testable hypotheses as responses to any one selective force. The effects of fragmentation by Plexaura A suggest that asexual reproduction via fragmentation has been selected for in this species. However, a complete demonstration that asexual reproduction has been selected ultimately must include analysis of the success of genotypes which rely on fragmentation versus that of genotypes which produce fewer fragments.

Acknowledgements. This research was supported by the University Awards Program of the Research Foundation of the State University of New York and NSF grant OCE 82-14894. I thank staff and scientists of the Smithsonian Tropical Research Institute and the Kuna Indians for making work in the San Blas Islands possible. Mary Alice Coffroth assisted with much of the field work and Louise Scrocchi assisted with the laboratory measurements. I thank Mary Alice Coffroth, William S. Clayton Jr. and 2 anonymous reviewers for comments and suggestions.

\section{LITERATURE CITED}

Birkeland, C. (1974). The effect of wave action on the population dynamics of Gorgonia ventalina Linnaeus. Stud. Trop. Oceanogr. 12: 115-126

Bothwell, A. M. (1981). Fragmentation, a means of asexual 
reproduction and dispersal in the coral genus Acropora. In: Gomez, E. D., Birkeland, C. E., Buddemeier, R. W., Johannes, R. E., Marsh, J. A., Tsuda, R. T. (ed.) Proc. Fourth Intl. Coral Reef Symp., Marine Science Center, University of the Phillipines, Quezon City, Vol. 2, p. $137-144$

Coates, A. G., Jackson, J. B. C. (in press). Morphological themes in the evolution of clonal and aclonal marine inv ertebrates. In: Jackson, J. B. C., Buss, L., Cook, R. E. (ed.) Population biology and evolution of clonal organisms. Yale University Press, New Haven

Cook, R. E. (1983). Clonal plant populations. Am. Sci. 71 : $244-253$

Gilmore, M. D., Hall, B. R. (1976). Life history, growth habits and constructional roles of Acropora cervicornis in the patch reef environment. J. sedim. Petrol. 46: 519-522

Glynn, P. W., Stewart, R. H., McCosker, J. E. (1972). Pacific reef corals of Panama: structure, distribution and predators. Geol. Rundsch. 61: 483-519

Harper, J. L. (1977). Population biology of plants. Academic Press, London

Highsmith, R. C. (1982). Reproduction by fragmentation in corals. Mar. Ecol. Prog. Ser. 7: 207-226

Highsmith, R. C., Riggs, A. C., D Antonio, C. M. (1980). Survival of hurricane-generated coral fragments and a disturbance model of reef calcification growth rates. Oecologia 46: 322-329

Hughes, T. P., Jackson, J. B. C. (1980). Do corals lie about their age? Some demographic consequences of partial mortality, fission and fusion. Science, N.Y. 209: 713-715

Jackson, J. B. C. (1977). Competition on marine hard substrata: the adaptive significance of solitary and colonial strategies. Am. Nat. 111: 743-767

Kinzie, R. A. III. (1974). Plexaura homomalla: the biology and ecology of a harvestable resource. Stud. Trop. Biol. 12: $22-38$

Knowlton, N., Lang, J. C., Rooney, M. C., Clifford, P. (1981).
Evidence for delayed mortality in hurricane-damaged Jamaican staghorn corals. Nature, Lond. 294: 251-252

Koehl, M. A. R. (1976). Mechanical design in sea anemones. In: Mackie, G. O. (ed.) Coelenterate ecology and behavior. Plenum Press, New York, p. 23-31

Koehl, M. A. R. (1977). Mechanical organization of cantileverlike sessile organisms: sea anemones. J. exp. Biol. 69: $127-142$

Lasker, H. R. (1983). Vegetative reproduction in the octocoral Briareum asbestinum (Pallas). J. exp. mar. Biol. Ecol. 72: $157-169$

Tunnicliffe, V. (1981). Breakage and propagation of the stony coral, Acropora cervicornis. Proc. natn. Acad. Sci. U.S.A. 78: $2427-2431$

Tunnicliffe, V. (1982). The effects of wave induced flow on a reef coral. J. exp. mar. Biol. Ecol. 64: 1-10

Vosburgh, F. (1977). The response to drag of the reef coral Acropora reticulata. In: Taylor, D. L. (ed.) Proc. Third Int. Coral Reef Symp., Vol. 1. University of Miami, Miami, p. $477-482$

Wainwright, S. A., Biggs, W. D., Currey, J. D., Gosline, J. M. (1976). Mechanical design in organisms John Wiley and Sons, New York

Walker, T. A., Bull, G. D. (1983). A newly discovered method of reproduction in gorgonian coral. Mar. Ecol. Prog. Ser. 12: $137-143$

Wilson, J. B. (1979). 'Patch' development of the deep-water coral Lophelia pertusa (L.) on Rockall Bank. J. mar. Biol. Ass. U.K. 59: 165-177

Woodley, J. D., Chornesky, E. A., Clifford, P. A., Jackson, J. B. C., Kaufman, L. A., Knowlton, N., Lang, J. C., Pearson, M. P., Porter, J. W., Rooney, M. C., Rylaarsdam, K. W., Tunnicliffe, V. J., Wahle, C. M., Wulff, J. L., Curtis, A. S. G., Dallmeyer, M. D., Jupp, B. P., Koehl, M. A. R., Niegel, J., Sides, E. M. (1981). Hurricane Allen's impact on Jamaican coral reefs. Science, N.Y. 214: 749-754 